\title{
Cuba:
}

\section{cambios económicos y sus impactos políticos y sociales}

\section{Olga Fernández Ríos*}

Resumen. En el proceso de transición socialista en Cuba, la actualización del modelo de desarrollo económico y social contempla la remoción del modelo estado-centrista y la apertura a sectores no estatales de la economía sin contravenir los logros de la Revolución cubana. La transformación muestra contradicciones y desigualdades sociales que pueden provocar confusiones y riesgos para mantener el consenso popular a favor del socialismo; contrarrestarlas depende del desarrollo económico. El artículo analiza el proceso de actualización del modelo, la rectificación en curso y los principales cambios llevados a cabo, así como sus impactos y desafíos políticos y sociales. El objetivo es contribuir al estudio de los factores sociales y políticos que interaccionan con los cambios económicos en pos de un socialismo sostenible y con más prosperidad, no sólo desde los prismas de la economía, sino desde la óptica de la política y de una ideología que se traduzca en motivaciones, compromisos, valores y cultura política masiva.

Palabras clave: proceso de actualización, desarrollo económico y social, justicia social, participación popular, Cuba.

*Investigadora del Instituto de Filosofía de La Habana, Cuba. 


\section{Olga FeRnÁndez Ríos}

\section{Cuba:}

\section{Economic changes and their political and social repercussions}

Abstract. In the process of the socialist transition in Cuba, the updating of the economic and social development model considers the stripping away of the state-centrist model and the opening to non-state sectors of the economy without infringing upon the achievements of the Cuban Revolution. The transformation reveals contradictions and social inequalities that may lead to uncertainty and risk in maintaining popular opinion in favor of socialism; addressing these problems depends upon economic development. This article analyzes the process of updating the model, the adjustment process that is now underway and the key changes taking place, as well as the political and social impacts and challenges. The aim is to contribute to the study of the social and political factors that are involved in the economic changes in search of a sustainable form of socialism and one with greater prosperity, not only from the viewpoint of the economy, but also from the political sphere, and from an ideology that translates into motivation, compromise, values and a broad political culture.

Keywords: updating process, economic and social development, social justice, popular participation, Cuba. 


\section{Introducción}

Los acuerdos aprobados en el VI Congreso del Partido Comunista de Cuba (PCC) (abril de 2011), en especial la ratificación de la estrategia de desarrollo socialista expresada en los «Lineamientos de la política económica y social del Partido y la Revolución», abrieron el proceso identificado como actualización del modelo de desarrollo económico y social cuyo núcleo es la transformación de las formas de propiedad con apertura a sectores no estatales de la economía. Ese proceso, fue también ratificado por el Séptimo Congreso del PCC (abril de 2016) en el que se introdujeron precisiones y planes para continuarlo.

El modelo de propiedad y gestión económica que se implementa reconoce la empresa estatal socialista como forma principal de la economía, las modalidades de inversión extranjera previstas en la ley (empresas mixtas, contratos de asociación económica internacional, entre otras), cooperativas agrícolas y urbanas, agricultores pequeños, usufructuarios, arrendatarios, trabajadores por cuenta propia y en pequeñas empresas y otras formas que en conjunto contribuyan a elevar la eficiencia económica (PCC, 2011).

Se trata de una nueva etapa de la transición socialista en Cuba, proceso complejo y contradictorio que tiene lugar en un país subdesarrollado y asediado por Estados Unidos. En esas condiciones es imprescindible dejar de lado las estructuras y prácticas del modelo estado centrista que, a pesar de los avances logrados por la Revolución durante más de cincuenta años, requería de una rectificación más profunda que otras realizadas en el país. Ello en nada desdice los logros de la Revolución cubana, además se constata que existen estructuras, mecanismos sociopolíticos y capacidades de autocrítica que posibilitan rectificaciones para eliminar deformaciones 


\section{Olga Fernández Ríos}

burocráticas que de manera tan negativa marcaron las experiencias socialistas del siglo XX, a cuya influencia Cuba no fue ajena (Ríos, 2014).

La transformación del modelo económico saca a flote contradicciones y desigualdades sociales susceptibles de provocar percepciones contradictorias de los cambios, que generan confusiones y riesgos para mantener el consenso popular a favor del socialismo, de ahí que es un imperativo contrarrestarlas, hecho que depende en gran medida del desarrollo económico. En eso se trabaja y es objetivo de la actualización, pero requiere tiempo, por tanto en el corto plazo son decisivas las acciones en el campo de las relaciones políticas e ideológicas que visibilicen la reafirmación del poder conquistado por el pueblo cubano desde 1959.

En tan pocas páginas no es posible realizar un análisis abarcador de tan complejo proceso y sus consecuencias, de manera que me enfocaré sólo en algunas de sus facetas que muestran el carácter sociopolítico de la actualización del modelo de desarrollo que involucra y pone en tensión el sistema político cubano bajo la dirección del PCC, con multifacéticas responsabilidades que atañen al Estado y al pueblo organizado. El objetivo es contribuir al análisis de factores sociales y políticos que interaccionan con los cambios económicos en pos de un socialismo sostenible y con mayor prosperidad, no únicamente desde los prismas de la economía, sino desde la óptica de la política y de una ideología que se traduzca en motivaciones, compromisos, valores y cultura política masiva.

Entre los temas susceptibles de analizar se seleccionaron tres: 1. antecedentes de la actualización del modelo de desarrollo económico y social, 2. la rectificación en marcha y los principales cambios que se implementan, 3. impactos y desafíos políticos y sociales que provocan esos cambios. 


\section{Antecedentes del proceso de actualización del modelo de desarrollo económico y social ${ }^{2}$}

El triunfo de la Revolución cubana el primero de enero de 1959 propició una profunda transformación en la sociedad y en gran medida eliminó las desigualdades sociales, la ignorancia y el legado de neocolonialismo y dependencia manifiestas a lo largo del siglo XX. Desde sus inicios se abrió un proceso de transición socialista, se consolidó el poder político en manos del pueblo con avances económicos, educacionales y culturales sin precedentes, junto con seguridad y dignidad. Una de las características de la transición socialista en Cuba ha sido garantizar justicia social como principal premisa del avance económico.

Para lograrlo, por diversas razones, se implementó un modelo de desarrollo en el que la estatización de gran parte de los medios de producción y la planificación económica fueron predominantes, junto con el desarrollo del sector cooperativo limitado a la agricultura. Éste fue tempranamente incorporado en el proyecto revolucionario, lo que se propició con la adopción de la Ley de Reforma Agraria (17 de mayo de 1959) que eliminó los latifundios de empresas estadounidenses y oligarcas nacionales y refrendó el derecho de los que trabajaban la tierra convirtiéndolos en sus propietarios. Esa ley favoreció la creación de cooperativas para la producción de caña de azúcar en $1960 .{ }^{3}$ Desde entonces se han desarrollado diversas

${ }^{2}$ Considerando que en este trabajo varias veces se hará refererencia a ese proceso en ocasiones se identificará como «proceso de actualización» o «la actualización».

${ }^{3}$ Las cooperativas cañeras se constituyeron sin contar con experiencia para impulsar formas de cooperación entre campesinos pequeños y medios, lo que se evidenció en problemas organizativos y de funcionamiento que condujeron a su desmontaje en 1962 hasta que se crearan condiciones favorecedoras del avance de las cooperativas. Para ampliar véase Rodríguez (1983). 


\section{Olga Fernández Ríos}

experiencias de formas de producción agrícola cooperada (Nova, 2004; Jiménez, s/f).

En todos los casos ha existido voluntad política para sostener y ampliar esta forma de propiedad y gestión compatible con los propósitos y objetivos de la transición socialista, a la vez que se ha brindado apoyo material y acceso a nuevas tecnologías desarrolladas por investigaciones científicas en instituciones estatales.

Las cooperativas agrícolas introdujeron cambios en la estructura de la propiedad de la tierra y en las relaciones laborales al propiciar una masiva conversión de trabajadores agrícolas en propietarios. Se insertaron en el contexto del predominio de la propiedad estatal sobre gran parte de los medios de producción y se lograron positivos niveles de eficiencia económica e influencia en el desarrollo de zonas rurales y municipios. Hasta el momento se ha demostrado que es una forma de propiedad y gestión económica compatible con los objetivos de la transición socialista, lo cual favoreció la creación de cooperativas urbanas a partir de 2012.

Debe reconocerse que el modelo estado-centrista que predominó en Cuba hasta 2011 propició desarrollo económico, sociopolítico y cultural junto con garantías de empleo, salud, educación y previsión social de acceso universal y alto grado de cohesión y de solidaridad interna y hacia el mundo. Asimismo, se reconoce que junto con importantes logros en políticas de justicia social promovió gratuidades o bajos precios a servicios amparados por el Estado y subsidios al 100 por ciento de la población, independientemente del aporte de los ciudadanos al desarrollo del país, lo

En 1963 se aprobó una segunda ley de reforma agraria que amplió el número de pequeños agricultores y diversificó la producción agrícola lo que posibilitó la posterior creación de nuevas cooperativas agrícolas. 
que tuvo negativas influencias en la productividad y en las mentalidades de las personas con afectación a las motivaciones laborales. Se trata del denominado «paternalismo estatal» que promovió concepciones de homogeneidad e igualdad social centradas, entre otros aspectos, en los subsidios a la distribución de bienes de consumo y un sobredimensionamiento del empleo en áreas administrativas en dependencias del Estado. A ello se sumaron disfunciones institucionales y el recrudecimiento del burocratismo, que en algunos casos favoreció el mercado negro y las manifestaciones de corrupción.

Alrededor de 1985 fue evidente la necesidad de realizar ajustes socioeconómicos, desde ese periodo se ubican los antecedentes más cercanos del proceso de actualización analizados en los siguientes tres epígrafes:

1. El proceso de rectificación de errores y tendencias negativas a partir de 1984. A mediados de los 1980, la dirección de la Revolución encabezada por Fidel Castro reconoció los errores y tendencias negativas que afectaban el desarrollo económico y alimentaban el burocratismo por lo que se abría un proceso para su análisis y rectificación. ${ }^{4}$ Lamentablemente el proceso se interrumpió a principios de la década de 1990 ante la necesidad de enfrentar las negativas afectaciones económicas que provocaba el derrumbe del socialismo en la Unión Soviética. A pesar de ello, fue una experiencia y muestra de voluntad política para eliminar las insuficiencias y deformaciones económicas derivadas de la excesiva centralización estatal de la economía y también para lograr mayor desarrollo económico con fundamento

${ }^{4}$ Se iniciaron ensayos para la introducción de mecanismos de mercado en la gestión empresarial con algunas descentralizaciones de decisiones y otras medidas, como la distribución de productos de consumo a través del mercado paralelo que liberaba productos con relación a la libreta de abastecimientos y medidas y contramedidas adoptadas con relación al mercado libre campesino (Ferriol, 1998). 


\section{Olga Fernández Ríos}

en las capacidades internas. Se comenzó entonces a fortalecer sectores económicos favorables al desarrollo humano, por ejemplo el científico en el campo de la biomedicina, la biotecnología, la ingeniería genética, junto con la producción de medicamentos y vacunas. También se avanzó en el desarrollo agropecuario en esferas de la salud y alimentación animal.

2. Los años 1990 de periodo especial. Es una etapa marcada por los efectos del derrumbe del socialismo este-europeo, la desaparición del Consejo de Ayuda Mutua Económica (CAME) — alianza en la que Cuba realizaba el mayor intercambio económico, financiero y científico-técnico- y la agudización de la agresividad política, económica y mediática de Estados Unidos contra Cuba por medio de dos leyes que reforzaron el bloqueo económico y comercial, la Torricelli en 1992 y la Helms Burton en 1997 con alcance extraterritorial. ${ }^{5}$ En los albores de ese contexto, después de un amplio debate nacional, el IV Congreso del Partido Comunista (1991) aprobó una apertura económica que requirió una reforma a la Constitución en julio de 1992 en la que se precisó que la propiedad socialista se ejerce sobre los medios fundamentales de producción y no sobre todos.

En ese tiempo se crearon las Unidades Básicas de Producción Cooperativa (UBPC) en las actividades agrícolas ${ }^{6}$ y se perfiló la apertura de sectores no estatales de la economía, el desarrollo del turismo internacional, la inversión extranjera y la descentralización del sistema bancario. Para

\footnotetext{
${ }^{5}$ «Algunos datos evidencian que el consumo en 1993 cayó en casi un 30 por ciento con relación a 1989, a la vez que se expandió la economía subterránea y el subempleo. Se estima que el número de subempleados en 1993 llegó a un millón de personas. Con la desaparición del CAME entre 1989 y 1993 las exportaciones cayeron en 77 por ciento y las importaciones 75 por ciento» (Ferriol, 1998:40-42).

${ }^{6}$ Los miembros de las UBPC son propietarios de los medios de producción, disponen de área para autoconsumo colectivo, se apropian del excedente y poseen un sistema de autogestión en el marco de un plan estatal.
} 
evitar la dolarización de la economía, en 1994 —además del peso cubano (CUC)-, entró en circulación el peso convertible que sustituyó al dólar en las transacciones comerciales y el mercado interno, lo que se tradujo en una dualidad monetaria que se mantiene hasta el presente. ${ }^{7}$ Es el periodo en que surgieron inequidades en los ingresos de la población y la imposibilidad de que los ciudadanos tuvieran acceso a los mercados de divisas y del turismo. Todo ello complicó la estructura socioclasista y abrió la tendencia hacia su heterogeneidad. Sin embargo, lo más importante fue que se preservaron la Revolución cubana y sus esenciales logros.

3. Primera década del siglo XX. Es una década en la que se produjeron importantes diagnósticos sobre problemas y contradicciones presentes en la sociedad cubana. Sobresale la intervención de Fidel Castro en la Universidad de La Habana (17 de noviembre de 2005) en la que retomó el tema de la construcción del socialismo y alertó sobre complejidades y vulnerabilidades en las esferas del desarrollo económico y social que podían arriesgar la continuidad de la Revolución (Castro, 2005). De igual manera, el debate popular que generó el discurso de Raúl Castro el 26 de julio de 2007 en la provincia de Camagüey con referencias a deformaciones que afectaban el desarrollo del país, entre ellas las vinculadas con el funcionamiento institucional y el crecimiento

\footnotetext{
${ }^{7}$ Paralelamente, se abrieron mercados agropecuarios y de bienes industriales y artesanales con precios liberados después de cumplidos los compromisos de venta al Estado. En 1997 se creó el Banco Central, se descentralizaron bancos e instituciones financieras y se adoptaron nuevas formas de organización y gestión económica con posibilidad de inversión extranjera en asociación con el Estado. Se ensayó un sistema de autofinanciamiento empresarial en divisas convertibles y de exportación e importación directa. Se despenalizó la posesión de divisas y se autorizó la recepción de remesas desde el extranjero. Todo ello en medio de proyectos injerencistas de Estados Unidos para promover la «transición democrática en Cuba», un intento de retorno al capitalismo. En adición, se realizaron acciones terroristas para sabotear el turismo internacional.
} 
del burocratismo. ${ }^{8}$ A la vez se desarrollaron investigaciones en el campo de las ciencias sociales en torno a su participación popular, democracia, agricultura, cooperativismo, desarrollo local, desigualdades sociales, así como estudios sobre raza, género, situación demográfica y manifestaciones de corrupción, lo que constata que el análisis político sobre los cambios por realizar y las decisiones adoptadas se han acompañado de estudios científicos. ${ }^{9}$

\section{La rectificación en marcha y los principales cambios que se implementan}

En los tres momentos reseñados hay muestras de voluntad política para desplegar nuevas condiciones socioeconómicas que garantizaran el desarrollo

${ }^{8}$ Aún bajo los efectos del periodo especial se enfrentó la injerencia de Estados Unidos y se desplegaron masivas acciones para lograr el regreso a Cuba del niño Elián González, víctima de las políticas estadounidenses que incentivan la emigración ilegal que lo separó de su padre y para exigir la liberación de cinco antiterroristas encarcelados en Estados Unidos. Por iniciativa de Fidel Castro se desarrolló la Batalla de Ideas que involucró organizaciones juveniles y de masas en el desarrollo de proyectos educacionales, de salud pública y culturales; se formaron trabajadores sociales para atender los sectores de la población más vulnerables. Se estiman en más de 150, los planes de desarrollo integral de la Batalla de Ideas (véase Cruz, s/f). ${ }^{9}$ Particular importancia han tenido investigaciones sobre el sector agrícola y cooperativo del Programa FLACSO, el Centro de Estudios de la Economía Cubana y el Centro de Estudios Demográficos de la Universidad de La Habana; la Universidad Central Marta Abreu de Las Villas y el Centro de desarrollo de Cooperativas de la Universidad de Pinar del Río. También investigaciones del Centro de Investigaciones Psicológicas y Sociológicas, en el área de estructura socioclasista y de estudios sobre juventud; el Centro Cubano de Antropología sobre estudios raciales; el Instituto de Filosofía sobre teoría acerca del socialismo, democracia, participación popular y propiedad social; el Centro de Desarrollo Local y el Instituto de Literatura y Lingüística. Además, han influido análisis promovidos por el Polo Científico de Humanidades y los Consejos de Ciencias Sociales provinciales. Académicos de varias instituciones han formado parte de grupos de trabajo que brindan asesoría a entidades con responsabilidad en la toma de decisiones. 
del país sin abandonar los objetivos socialistas. Ese propósito se concreta de modo más integral a partir del Sexto Congreso del PCC en 2011 con la actualización del modelo económico que significa el desmontaje del socialismo estado-céntrico y es más coherente con la transición socialista en una coyuntura internacional adversa, marcada por dos negativos factores: el impacto de la crisis del capitalismo en las economías de los países menos desarrollados y el mantenimiento del bloqueo económico y comercial de Estados Unidos impuesto contra Cuba desde hace más de cincuenta años. ${ }^{10}$

El proceso de actualización contempla que la experiencia histórica ha demostrado que no se trata de que el Estado asuma directamente la administración de toda la propiedad, sino que debe ser capaz de decidir entre lo que es fundamental para los objetivos socialistas y lo que no lo es. Lo primero conlleva garantizar el avance hacia la emancipación social y el cumplimiento de objetivos estratégicos; lo segundo, se refiere a lo que no es esencial al socialismo pero que le puede ser complementario. A la vez posibilita que el Estado se concentre en garantizar los objetivos socialistas. En ese sentido, los cambios que se implementan se proponen eliminar la desproporcionada centralización y control estatal de prácticamente toda la esfera económico-productiva y de servicios, lo que distorsionó el concepto propiedad

${ }^{10}$ En Cuba desde 1968, con la «ofensiva revolucionaria» se generalizó la propiedad estatal sobre los medios de producción, excepto la pequeña propiedad de la tierra y el sector cooperativo en la agricultura. Entonces se sobredimensionaron las fuentes de empleo en dependencias del Estado y se recargó su responsabilidad en sectores administrativos y de servicios lo que propició fuentes para el mercado subterráneo a costa de los recursos del Estado. Vale la pena recordar que la lógica marxista reconoce la importancia de garantizar que los principales $o$ fundamentales medios de producción, no estén en manos privadas, sino que respondan a los intereses de los sectores populares. Esto tiene que ver con factores cualitativos y no cuantitativos en la definición de la propiedad en el socialismo. Reducirla a la forma estatal, desvirtuó el papel del Estado y desató una cadena de alteraciones en diferentes esferas de la sociedad. 
social, extendió la burocracia y desalentó la iniciativa local. Asimismo, se desmontan patrones de corte paternalista e igualitarista que tuvieron negativas consecuencias en el desenvolvimiento económico, en las actitudes y motivaciones laborales y en la productividad.

La ratificación de la estrategia de desarrollo socialista va acompañada de un sentido de continuidad que no excluye nuevos ajustes que complementen dialécticamente lo coyuntural y lo estratégico, y a diferencia de otras etapas la actualización que hoy se emprende transforma algunas de las funciones que debe cumplir el Estado. Además de la extensión de las formas de propiedad y gestión se han introducido recortes a entidades administrativas estatales con un reordenamiento de la fuerza laboral, mayor autonomía y responsabilidad empresarial, descentralización de facultades hacia provincias y municipios, perfeccionamiento de mecanismos de disciplina económica y contractual, entre otras.

Cabe mencionar que la actualización inició con una extensión del trabajo por cuenta propia, sector que no contradice las formas de propiedad social." $\mathrm{Al}$ respecto, en el Informe Central al VII Congreso del PCC se reconoce que el incremento de ese sector y la autorización de la contratación de fuerza de trabajo ha propiciado la existencia de medianas, pequeñas y

${ }^{11}$ El término «trabajo por cuenta propia» identifica relaciones económicas diferentes, ya que incluye por igual a empleadores y a empleados que no trabajan en dependencias del Estado. Es un sector necesario que cubre un nicho de producción mercantil y servicios a pequeña escala con impactos en la generación de empleos y la ampliación de servicios a la población, descargando al Estado de gestiones que le ocupaban de forma sobredimensionada y sin posibilidades de resolver necesidades en una amplísima gama de productos y servicios. En la actualidad existen alrededor de 370 mil «cuentapropistas», 80 por ciento de ellos integrado a sindicatos obreros organizados por ramas de la producción y los servicios. Estar sindicalizados los inserta en un importante canal participativo con posibilidades de influencia en el ulterior perfeccionamiento del «cuentapropismo» y en el análisis del desarrollo del mundo laboral cubano. 
microempresas privadas que hoy funcionan sin la debida personalidad jurídica y se rigen ante la ley por un marco regulatorio diseñado para las personas naturales dedicadas a pequeños negocios que se realizan por el trabajador y su familia. Se ratifica también que en las formas de gestión no estatales no se permitirá la concentración de la propiedad ni de la riqueza a la vez que la empresa privada actuará con límites bien definidos y que constituirá un elemento complementario del entramado económico del país (Castro, 2017).

Como reconocimiento de la trascendencia que han tenido las cooperativas en la agricultura y en el desarrollo de las zonas rurales, la actualización amplía el sector cooperativo a zonas urbanas en variados servicios que abarcan la gastronomía, la construcción, el transporte, en conjunto con la producción de bienes de interés nacional. ${ }^{12}$

El trabajo por cuenta propia y el cooperativismo urbano se despliegan en los marcos locales y forman parte de una estrategia de desarrollo territorial con regulaciones a través de la política tributaria sobre ingresos y sobre fuerza de trabajo. Con relación al trabajo por cuenta propia, si bien tributa a la economía del país, amerita valorar sus límites y equilibrios en cuanto al carácter del trabajo de los contratados o asalariados de este sector, y a la apropiación privada de los excedentes. Por el contrario, el sector cooperativo tiene mayores potencialidades para desarrollar una concepción de economía solidaria mucho más afín a la transición socialista. Incluso deben propiciarse condiciones que estimulen la conformación de cooperativas en esferas donde ahora se expande el «cuentapropismo». ${ }^{13}$

${ }^{12}$ En la actualidad hay más de 360 cooperativas urbanas en áreas de la construcción, la gastronomía, los servicios, y otras asociadas a la producción de bienes a pequeña escala.

${ }^{13}$ Entre noviembre y diciembre de 2012 fueron aprobados el Decreto Ley 305 del Consejo de Estado y otras normas jurídicas para la creación de cooperativas no agropecuarias en todas las provincias del país. A partir de esas normativas en 2013 inició una etapa experimental 


\section{Olga Fernández Ríos}

La diversidad de formas de gestión se articula gracias a la planificación socialista actualizada, por lo que se llevan a cabo transformaciones metodológicas, organizativas y de control, al mismo tiempo que contempla el mercado, influyendo sobre él y considerando sus características, con el fin de no reproducir las anteriores deformaciones de centralización burocrática.

Con las medidas adoptadas se pretende fortalecer una economía que sustente el socialismo y reconozca que no puede haber espacio para terapias de choque, ni decisiones que pongan en peligro el control socialista de la economía y la soberanía sobre los recursos. En cuanto a esto, Raúl Castro ha precisado que el incremento del sector no estatal de la economía, lejos de significar una privatización de la propiedad social, convoca a convertirse en un factor facilitador para la construcción del socialismo, pues permitirá al Estado concentrarse en la elevación de la eficiencia de los medios fundamentales de producción y desprenderse de la administración de actividades no estratégicas para el país (Castro, 2011).

El Séptimo Congreso ratificó las políticas trazadas en esa dirección y mostró varios avances con el propósito de garantizar su continuidad y perfeccionamiento:

a) Proponer una proyección más clara y definida sobre la construcción del socialismo, que se recoge en dos documentos sometidos a debate popular para su aprobación: la conceptualización del nuevo modelo de desarrollo económico y sociopolítico y el plan de desarrollo económico hasta

con 230 nuevas cooperativas urbanas en diversas esferas productivas y de servicio. Tienen personalidad jurídica con fines económicos y sociales; se crean por decisión voluntaria de sus socios y funcionan a partir de gestión colectiva de todos los integrantes. Las cooperativas urbanas se unen a las cooperativas agrícolas y al trabajo por cuenta propia, cumplimentando los Lineamientos económicos 25, 26, 27, 28 y 29 aprobados por el VI Congreso del PCC (PCC, 2011). 
el 2030. En ambos se reconoce el lugar primordial del sector estatal de la economía y el papel complementario del sector no estatal.

b) Propiciar una mejor comprensión acerca de las correlaciones entre economía y política.

c) Profundizar en la ruptura con viejos esquemas sociopolíticos asociados al modelo de desarrollo previo.

d) De modo más evidente se concibe la actualización del modelo de desarrollo con una concepción sistémica de la sociedad y se valoran los problemas estructurales, funcionales y subjetivos que afectan el proceso de cambios y ajustes que se realizan.

e) Se evalúa con mayor integralidad la influencia de los cambios en conductas, valores, proyectos de vida personal, sentimientos y actitudes de las personas, así como en la ideología dominante.

Lo cier to es que hoy se promueven análisis y debates que contribuyen a lograr una concepción más abierta del proyecto socialista y sus metas. Las complejidades de la transición socialista se analizan con una visión sistémica de la sociedad que abarca temáticas de diferente corte como propiedad social y trabajo, justicia social, democracia, vínculo entre ética y política, individualidad, espacios públicos, función de los medios de comunicación y problemas migratorios y demográficos. Asimismo, se examina la relación entre planificación y mercado, y la necesidad de eliminar el paternalismo estatal con un apropiado equilibrio entre gratuidades y subsidios, en tanto que se mantiene la protección de los derechos ciudadanos en materia de empleo, seguridad social, salud pública y educación. 


\section{Impactos y desafíos sociopolíticos que provocan los cambios}

La actualización es un proceso de rectificación más profundo que los anteriores efectuados en Cuba, los cuales no alteraron la concepción de un Estado que liberaba a las personas de muchas responsabilidades, mientras que en la actualidad los elementos estables de la relación entre individuo y Estado modifican aquello que influye en todas las esferas de la sociedad. En efecto, los cambios en el ámbito económico provocan impactos sociales y políticos que a la vez constituyen desafíos por enfrentar; entre ellos se resaltan los que se producen en tres direcciones, descritas a continuación.

La primera engloba el perfeccionamiento institucional indispensable en los marcos del sistema político que incluye al Partido Comunista, al Estado y al sistema de organizaciones políticas y de masas con fuerte influencia en la sociedad civil. También se asocia con la mejora de los métodos de dirección, el balance entre centralización y descentralización y el enfrentamiento al burocratismo. La segunda tiene que ver con la ampliación de la participación popular, y la tercera con la permanente revisión de las consecuencias que los cambios ocasionan en la vida de las personas, en sus proyectos y subjetividades; en actitudes y valores; y en las políticas de justicia social que forman parte de las bases de la Revolución cubana. Todo ello requiere una constante sensibilidad para auscultar los impactos que las medidas adoptadas tienen sobre la población y las políticas de justicia social. 


\section{El perfeccionamiento institucional}

Desde 1959 la institucionalidad del país ha sido objeto de atención y ajuste; ${ }^{14}$ no obstante, por diversas razones se produjeron confusiones en ciertos cometidos institucionales, deformaciones burocráticas y formalismo. Se trata de problemas que se analizan críticamente para su rectificación. Referente a ello, el VI y el VII Congresos del PCC se orientaron en lograr una mayor precisión en torno a las funciones que corresponden al partido, al Estado y a los sectores organizados de la sociedad civil.

En todo momento se ha reconocido que los componentes del sistema político cubano son perfectibles ${ }^{15}$ y que muchos de los problemas y las debilidades que han existido son funcionales o de carácter subjetivo, como las confusiones de las tareas de gobierno y de corte administrativo a escala local y entre las funciones del Partido Comunista y las Asambleas del Poder Popular.

El VI Congreso partidista analizó esos y otros problemas con la urgencia de solucionarlos y de precisar y respetar las correspondientes actividades acorde con la autoridad que compete a cada institución, según la

${ }^{14}$ En cuanto a la institucionalidad es preciso recordar los procesos surgidos desde 1959, por ejemplo la creación del Partido Comunista con amplia base popular de su integración y su vocación unitaria martiana y marxista; la aprobación de la Constitución socialista y del sistema político encabezado por el partido y con el Estado representante de un único poder definido como Poder Popular, con canales participativos y representativos propios; la temprana formación de organizaciones sociales de base popular, junto con otras entidades de la sociedad civil que inciden en el sistema político y la participación popular.

${ }^{15}$ Desde el establecimiento de los Órganos del Poder Popular en 1976 se han hecho ajustes con el propósito de conseguir mayor vinculación con las bases. En 1992 el sistema electoral y la Constitución fueron reformados después de un extenso debate popular, se amplió la democracia directa en la elección de delegados provinciales y diputados y se llevaron a cabo ajustes acorde con el desarrollo del país. 


\section{Olga Fernández Ríos}

Constitución de la República. ${ }^{16} \mathrm{Al}$ respecto aprobó la «Resolución sobre el perfeccionamiento de los Órganos del Poder Popular, el sistema electoral y la división político administrativa» y medidas para lograr mayor coherencia entre las diferentes esferas de la sociedad, los niveles centrales del Estado y del gobierno y las bases locales con equilibrio entre centralización y descentralización de funciones y responsabilidades.

Eso incluye, por una parte, conceder mayor autonomía a las bases locales, a los municipios y provincias, a la vez que se despliegan proyectos comunitarios; y por otra, eliminar la gestión directa del Estado en las empresas con diferenciación entre lo estatal y lo empresarial. ${ }^{17}$ Esto también concierne a la planificación socialista que seguirá siendo la vía principal para la dirección de la economía, por lo que se fortalecen sus aspectos metodológicos, organizativos y de control en nuevas condiciones que requieren tener en cuenta el mercado para influir en sus límites y evitar que se distorsione su función en un país de proyección socialista.

En términos de institucionalidad existen diversos imperativos con relación al Estado, puesto que los cambios en la estructura económica y productiva precisan de instituciones estatales mejor organizadas y más eficientes, capaces de cumplimentar sus importantes responsabilidades con la finalidad de transitar hacia una estructura de propiedad más abierta y multilateral, que amplíe variantes de propiedad, organización productiva

\footnotetext{
${ }^{16}$ Véanse artículos 5, 6, 7, 8 y 9 de la Constitución de la República de Cuba que precisan las funciones y deberes del Partido Comunista de Cuba, la Unión de Jóvenes Comunistas y el Estado.

${ }^{17}$ Además de aprobar dicha resolución se inició un experimento en las provincias Artemisa y Mayabeque para estudiar una reforma del artículo 117 que separe los cargos y las atribuciones del presidente de las Asambleas Municipales y Provinciales del Poder Popular y de sus Consejos de Administración con la intención de erradicar disfunciones al estar unidos en una misma persona (Diario Granma, 2011).
} 
y servicios que no pongan en riesgo los objetivos socialistas. ${ }^{18} \mathrm{~A}$ lo anterior se agrega el fortalecimiento del derecho en un afán por avanzar en un reordenamiento de leyes y disposiciones imprescindibles para el país.

El perfeccionamiento institucional que se ejecuta incluye redimensionamiento del aparato del gobierno, reducción de plantillas innecesarias en el sector administrativo, propuestas para establecer límites en el ejercicio de los cargos, acciones judiciales contra la corrupción y políticas que simplifiquen algunos trámites. Se avanza hacia la creación de un sistema de nombramiento, contratación y promoción de los funcionarios o administradores públicos. Además, se une la voluntad política para especificar las funciones del Partido Comunista y del Estado con la conciencia de que la excesiva identificación entre ambos obstaculiza el papel del partido y de los órganos estatales y de gobierno. Al mismo tiempo se insiste en cambiar métodos y estilos de dirección para que sean más ágiles y participativos, tema abordado en la Primera Conferencia Nacional del Partido Comunista de Cuba, celebrada el 28 de enero de 2012.

Mención especial merece el enfrentamiento al burocratismo, tarea compleja que integra condicionantes objetivas y factores subjetivos. Es un asunto clave que está en el centro de atención de la dirigencia del país con muy buena recepción en el pueblo. Se han concretado ya acciones para desmontar la distorsionada red de reglamentaciones y prohibiciones que

${ }^{18}$ El fortalecimiento del Estado en la transición socialista requiere consolidar el poder político que representa intereses populares en una etapa en la que aún existen contradicciones de clase de diferentes matices. En nada contradice el ideal marxista acerca de la extinción del Estado en etapas más avanzadas de la sociedad socialista cuando las contradicciones ya no existan ni sean amenazas para el avance de la nueva sociedad. Esta idea clave del marxismo fue distorsionada durante el estalinismo y en la experiencia posterior en la URSS, al punto de llegar a la estatalización extrema de la vida social. 


\section{Olga Fernández Ríos}

sobrepasan las lógicas normativas. Todavía más: urge desmontar el empoderamiento de sectores burocráticos alejados de las bases populares que son a las que deben tributar. Es un tema asociado con la selección y promoción de dirigentes, electos o designados, de ahí que la Primera Conferencia Nacional acordó objetivos encaminados a perfeccionar la política de cuadros de dirección, que incluye normas de selección y renovación, establece límites de tiempo y edades para el ejercicio de los cargos y determina estilos de dirección. Otros objetivos abordados se orientan a la evaluación de los dirigentes y a los controles a los que deben ser sometidos periódicamente. ${ }^{19}$

\section{La necesaria ampliación de la participación popular}

Junto con el perfeccionamiento institucional, otro desafío que se presenta para cumplimentar los objetivos de la actualización es ampliar el involucramiento popular en la toma de decisiones y en el control de los recursos y la gestión. Para ello es vital un permanente vínculo entre autoridades y pueblo, así como de altos niveles de participación popular, actividad que en Cuba muestra notables experiencias relacionadas con distintos medios para propiciar prácticas democráticas. El sistema de órganos del poder popular cuenta con canales participativos al igual que la sociedad civil con el sistema de organizaciones sociales masivas en las que participan los trabajadores y sus sindicatos, campesinos, mujeres, estudiantes y vecinos.

La interacción de ambas esferas aporta condiciones para una mayor calidad de la democracia si se considera que los ciudadanos se integran

${ }^{19}$ Véase el capítulo III «Política de cuadros», objetivos 76-82 (PCC, 2012). 
simultáneamente a diversas organizaciones que fungen como canales de expresión de opiniones e intereses (Ríos, 1995). Al mismo tiempo, debe reconocerse que ha existido desaprovechamiento de esos canales participativos, hoy necesitados de renovados bríos acorde con las nuevas condiciones y exigencias de la sociedad.

Es obvio que la consulta popular masiva puede reservarse para la toma de decisiones de alcance nacional y estratégico, pero es posible incrementar de modo estable la participación popular en la gestión pública local y en la promoción de iniciativas y proyectos comunitarios, laborales y sectoriales. Ese tipo de prácticas influye positivamente en una mayor incidencia de los variados actores sociales en la innovación de las formas de gobierno de manera descentralizada como parte y equilibrio de la gestión política y antídoto a las «lógicas» verticales de la burocracia en cualquier nivel.

Aunado a lo anterior, se revitaliza la participación popular cuando se potencian los nuevos actores sociales; es el caso del sector que no depende del Estado, pero cuya inclusión en la construcción colectiva de la sociedad socialista es ineludible. El hecho de que los ciudadanos se integren a diversas organizaciones sociales, como ocurre en Cuba, multiplica las opciones para hacer efectiva la participación popular al generar espacios de socialidad con influencia en la toma de decisiones, incluyendo las que afectan la vida cotidiana de las personas. Ello propicia también el equilibrio entre lo que corresponde a las instituciones y lo que potencia la participación popular, e influye para que las decisiones políticas se asuman como propias por toda la ciudadanía, un factor favorable a la renovación del consenso político en las condiciones que introduce el nuevo modelo de desarrollo económico y social. 


\section{Impactos sociales y retos en cuanto a la justicia social}

Dos elementos son básicos dentro del análisis enunciado. Primero, la ampliación de formas de propiedad favorece el surgimiento de diferencias sociales procedentes de variadas fuentes de ingresos generadas y de diferencias salariales que aún no han podido ser ajustadas. La estructura de la sociedad cubana hoy es más heterogénea con relación a etapas anteriores en las que la mayoría de la población estaba empleada en dependencias del Estado con patrones salariales bastante equilibrados. Eso ha cambiado, incluso hay manifestaciones y posicionamientos de corte clasista a partir de las distintas formas y montos de ingresos y salarios actuales.

Segundo, la actualización adopta medidas para minimizar el paternalismo estatal y las gratuidades indebidas que no han sido ajenas a la hipertrofia burocrática, la mentalidad de inercia y acomodo, las manifestaciones de corrupción y fomento de mercado subterráneo. Todo ello ocasiona dañinos reflejos ideológicos y éticos que penetran el tejido social y afectan la productividad y la civilidad indispensable en un proceso socialista.

Ambos elementos son trascendentes y requieren de permanente análisis con todos los sectores de la población para diferenciar el paternalismo de la justicia social. El primero conlleva una protección estatal deformante de los principios de igualdad y equidad que, además de recargar innecesariamente al Estado, propician distorsiones que obstaculizan el avance del socialismo, mientras que la justicia social es parte de los pilares fundamentales y del humanismo de la Revolución que ha mantenido el principio de avanzar en el crecimiento económico sin afectar las políticas públicas. Abarcan seguridad social y alimentaria, empleo, salud pública, educación, cultura, 
deporte y vivienda. ${ }^{20}$ Todavía hoy se mantienen importantes subvenciones estatales con un criterio universal que favorece a los más de 11 millones de cubanos (por ejemplo, para apoyar la canasta familiar básica).

Lo cierto es que en todo momento se han ratificado las políticas de justicia social considerando el reconocimiento de las diferencias sociales, aun clasistas, que subsisten en la construcción del socialismo. Debe hacerse a partir de la reivindicación del trabajo como vía esencial de realización personal y de desarrollo social y con la recuperación del principio de distribución, según el aporte del trabajo. Es un ámbito en el que se enfrentan importantes retos vinculados con el desarrollo de las fuerzas productivas y la eficiencia económica cuando la correlación entre los niveles de producción y consumo tiene desbalances y es imprescindible crear condiciones económicas para realizar ajustes a la política salarial. Los esfuerzos se orientan a la implementación de medidas que subsidien y protejan a sectores vulnerables, de ahí que la actualización incluye decisiones encaminadas a realizar subvenciones estatales conforme a las necesidades de personas y familias, en lugar de subvenciones al consumo de todos los ciudadanos.

Durante los VI y VII Congresos del PCC se confirmó que en Cuba no se eliminarán las políticas públicas de beneficio universal para todos los ciudadanos en salud, educación, seguridad social y alimentaria. Se desprende que se combinarán dos fórmulas de subsidio estatal: universal y diferenciado. En ambos casos el Estado será la principal garantía, pero acerca de los subsidios diferenciados a personas y familias con bajos ingresos, el nivel comunitario desempeña un papel definitorio, en particular en los subsidios relacionados con la construcción y reparación de viviendas.

${ }^{20}$ En el caso de la vivienda se reconoce que es un área necesitada de nuevos proyectos y planes. 


\section{Olga Fernández Ríos}

Lo anterior se relaciona con el rescate del principio de distribución socialista según el trabajo y se abre a formas superiores que tienen en cuenta las necesidades y el reconocimiento de la individualidad en el socialismo, tema en el que se profundiza por su valor intrínseco y con la finalidad de desmitificar una de las más dañinas interpretaciones dogmáticas sobre el socialismo, el cual plantea que en esa sociedad se anula lo individual al subordinarse a lo social. Dicha concepción se va revirtiendo a la vez que se enfrentan los factores que conspiran contra la plena realización de la individualidad. ${ }^{21}$

Tanto la justicia social como el lugar de la individualidad son reconocidos por la matriz marxista del socialismo y el humanismo de la Revolución cubana, que se diferencia sustancialmente del lema capitalista referido a la igualdad de oportunidades que supuestamente ese sistema propicia. En realidad es una falacia edificada en la base de un individualismo exacerbado y de una restricción interesada en la privatización de las responsabilidades estatales, lo que en la Cuba socialista no ocurrirá.

\section{Conclusiones}

Los VI y VII Congresos del PCC forman parte de un mismo proceso que busca transformar el modelo de desarrollo económico y social, objetivo legítimo que se sustenta en los intereses comunes del país, su pueblo y su gobierno.

${ }^{21}$ El análisis popular del Proyecto de Lineamientos que rige la actualización muestra el interés en cuanto a asuntos de gran relevancia para personas y familias; por ejemplo, la paulatina desaparición de la libreta de abastecimientos, junto con la política de precios, transportación, educación, calidad de los servicios de salud pública y la unificación monetaria. Sobre esos tópicos se recibió la mayor cantidad de propuestas de la población (Castro, 2011). 
Ese proceso inaugura una nueva etapa en el desarrollo de la Revolución cubana con el afán de implementar otro modo de construir el socialismo con una visión más integral de la sociedad que reconozca que, si bien no hay socialismo sin desarrollo de las fuerzas productivas ni condiciones para cubrir las necesidades de las personas, tampoco hay socialismo sólo con desarrollo económico.

Desde esa perspectiva, debe fortalecerse la función que desempeñan las instituciones políticas y las organizaciones sociales y de masas portadoras de gran responsabilidad en la calidad de la participación popular, método insoslayable para la legitimación de autoridades y decisiones. Se trata de esferas y acciones con directa influencia en la continuación de la transición socialista, objetivo bien definido en los documentos aprobados por los congresos mencionados. Con el fin de conseguirlo es necesario identificar los impactos de la actualización en el sistema político, en las personas y en las políticas públicas. Los tres casos representan nuevos retos por enfrentar, con el propósito de preservar los logros de la Revolución y favorecer la continuidad de la transición socialista en un contexto más complejo y contradictorio, y una sociedad más heterogénea que la existente hasta el año 2011.

Especial atención se le concede a los esfuerzos para auscultar los efectos que las medidas económicas tengan sobre la población y las políticas de justicia social y al freno de las desigualdades a través de acciones complementarias desde cualquier esfera de la sociedad. Debe existir un permanente monitoreo de esos efectos si se pretende continuar con las políticas de justicia social en condiciones de descentralización económica, presencia, divergencias socioclasistas y de reconocimiento del mercado regulado y no únicamente de la planificación estatal. 
Es evidente que la actualización se profundizará aún más y que su éxito depende de múltiples factores, entre los que sobresalen el avance económico y las formas de ejercicio de la política, vista como sistema que incluya a sus portadores institucionales y sus eventuales cuadros, además de jerarquizar la correlación entre ética y política. Es prioritario dar seguimiento a los horizontes individual y colectivo, y a los impactos de los cambios en el imaginario popular, en las subjetividades, en los valores, como factores clave en el ineludible empoderamiento popular que requiere el socialismo.

En todo el proceso, las potencialidades de éxito dependerán en gran medida de la identificación popular con la estrategia trazada y de las políticas encaminadas a lograr el predominio de una cultura socialista. Como sucedió en etapas tempranas del desarrollo de la Revolución cubana, se requieren profundos análisis y debates políticos y teóricos sin formalismos y con responsabilidad, para la mejor orientación de las modificaciones a implementar, evitar improvisaciones y tergiversaciones acerca de la construcción del socialismo.

El desafío estratégico integra tres condicionantes que la actualización debe garantizar: la preservación y ampliación de los niveles de prosperidad y desarrollo humano alcanzados en Cuba, el mantenimiento del consenso político y la permanente renovación de la hegemonía socialista con el predominio de condiciones económicas, sociopolíticas, culturales e ideológicas que contribuyan a reproducir relaciones y valores socialistas. 


\section{Referencias}

Castro Ruz, Fidel (17 noviembre de 2005), «Discurso pronunciado en el acto por el aniversario 60 de su ingreso a la universidad», Aula Magna de la Universidad de La Habana, Cuba, en http://www.cuba.cu/gobierno/discursos/2005/ esp/fl71105e.html

Castro Ruz, Raúl (17 de abril de 2011), «Informe Central al Vi Congreso del PCC», Diario Granma, en www.granma.cu/granmad/secciones/6to-congreso-pcc /artic-04.html

(17 de abril de 2016), «Informe Central al VII Congreso del PCC», Cubadebate, en http://www.cubadebate.cu/noticias/2016/04/17/informe-central-al-vii -congreso-del-partido-comunista-cuba/

Cruz Capote, Orlando (s/f), Informe de investigación (inédito), Fondo de la Biblioteca del Instituto de Filosofía, La Habana.

Diario Granma (agosto de 2011), «Sobre la experiencia a desarrollar en las provincias de Artemisa y Mayabeque», Diario Granma, 15(214), en http://www. granma.cu/granmad/2011/08/02/nacional/artic02.html

Fernández Ríos, Olga (1996), «Cuba: participación popular y sociedad», en Olga Fernández Ríos et al. (eds.), Participación en Cuba y los retos del futuro, La Habana, Ediciones CEA, pp. 37-55.

(julio de 2014), «La transición socialista en Cuba: ajustes económicos y desafíos sociopolíticos», Latin American Perspectives (4).

Ferriol Muruaga, Ángela (1998), «El empleo en Cuba (1989-1996)», en Ángela Ferriol Muruaga et al. (eds.), Cuba: crisis, ajuste y situación social (1990-1996), La Habana, Editorial de Ciencias Sociales, pp. 23-26.

Jiménez Guethón, Reynaldo Miguel (s/f), «Desarrollo local y cooperativas agrícolas en Cuba: logros y desafíos», Revista África-América Latina (46), en http:// 


\section{Olga Fernández Ríos}

publicaciones.sodepaz.org/images/uploads/documents/revista046/5_desarro llolocal.pdf

Nova, Armando (2004), El cooperativismo línea de desarrollo en la agricultura cubana 1993-2003, Cuba, Universidad de La Habana.

Partido Comunista de Cuba (PCC) (2011), Lineamientos de la política económica y social del Partido y la Revolución, en www.cubaweb.cu/secciones /6to--congreso-pcc/folleto\%lineamientos

(18 de abril de 2011b), «Resolución sobre el perfeccionamiento de los Órganos del Poder Popular, el Sistema Electoral y la División Político Administrativa», Cubadebate, en www.cubadebate.cu/especiales/2011/04/18/reso lucion-sobre-el-perfeccionamiento-de-los-organos-del-poder-popular-elsistema-electoral-y-la-division-politico-administrativa (29 de enero de 2012), «Objetivos de trabajo del Partido Comunista de Cuba aprobados por la Primera Conferencia Nacional», Diario Granma, en www.granma.cu/granmade/secciones/lra-conferencia-pcc/objetivos.html Rodríguez, Carlos Rafael (1983), Cuatro años de Reforma Agraria, La Habana, Editorial de Ciencias Sociales. 